\section{A new method of salvaging nipple projection after secondary nipple reconstruction using locoregional flap}

Sir,

The most important features of a natural reconstructed nipple are symmetry and a durablevalidvertical projection. A frequent drawback of the methods currently used for nipple reconstruction is the loss of nipple projection in the longer post-operative term. Although numerous nipple-areolar complex reconstruction techniques have been described, ${ }^{[1-3]}$ common among these techniques is a failure to maintain a nipple projection over time (estimated at $17 \%-75 \%$ ), and difficulties related to maintenance of nipple projection have been well documented. ${ }^{[4]}$

As proposed by Caterson et al. for nipple-areolar projection, ${ }^{[1]}$ we present a surgical technique that uses a purse-string to increase nipple projection.

Our surgical procedure is carried out under local anaesthesia (mepivacaine 2\%); first, using the contralateral nipple diameter as a template, we made 6-8 small triangular skin incisions with an 11 blade scalpel; the incision of each triangle's base is equally spaced $2 \mathrm{~mm}$ outside the desired nipple diameter. These triangle-shaped areas are deepithelialised; then, through an incision site, a purse-string suture (cervical visor-3 Gore-Tex) on a straight needle is subsequently inserted and continued through all the incisions and is placed within the deep dermis [Figure 1]. This suture material is uniquely suited due to the following property: it is strong and permanent, and it slides very easily through the tough dermal layer. Gentle traction is applied until there is good projection, and the purse-string suture is tied under moderate tension. The wounds are closed in double layers.
A 'donut' dressing is applied to avoid compression of the nipple for 4 months postoperatively.

In our clinic, this method was used with nine women (one bilateral case and eight unilateral cases of loss of nipple projection). They were no cases of infection, nipple ischaemia or other complications.

No permanent sutures required removal for infection or exposure.

Our experience using this technique has provided a stable projection of the nipple with at least 1-year follow-up represented in pre- and post-operative photographs, as shown in Figure 2. There were no deformities of the nipples or the areolas after this procedure and no decrease in the nipples or areolas size; the triangular vertical skin excisions around the nipple avoid the skin excess during the nipple lift.

This method is very simple in concept and procedure without a complicated design; it does not require

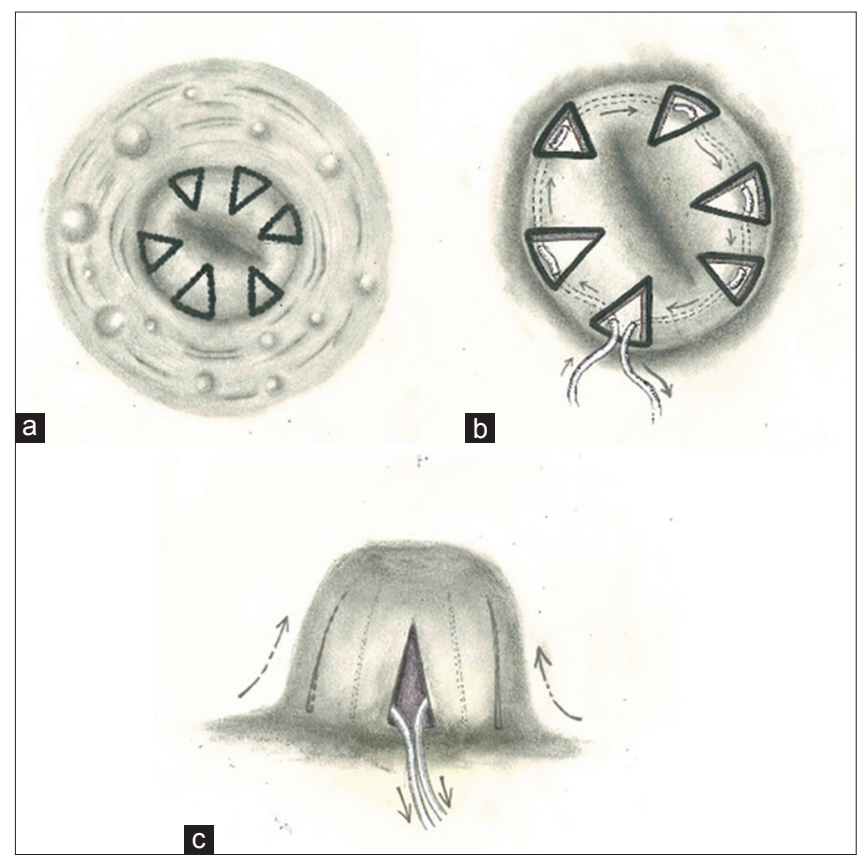

Figure 1: Schematic drawings of the operation. (a) 6-8 small triangular skin incisions are evenly spaced (with the base of each triangle approximately $2 \mathrm{~mm}$ outside the desired nipple diameter) with an 11 blade scalpel; these triangle-shaped areas are deepithelialised; (b) Purse-string suture used to form an internal supporting ring and it is tied under moderate tension; (c) the nipple access sites are closed with 5-0 monocryl and 6-0 nylon 


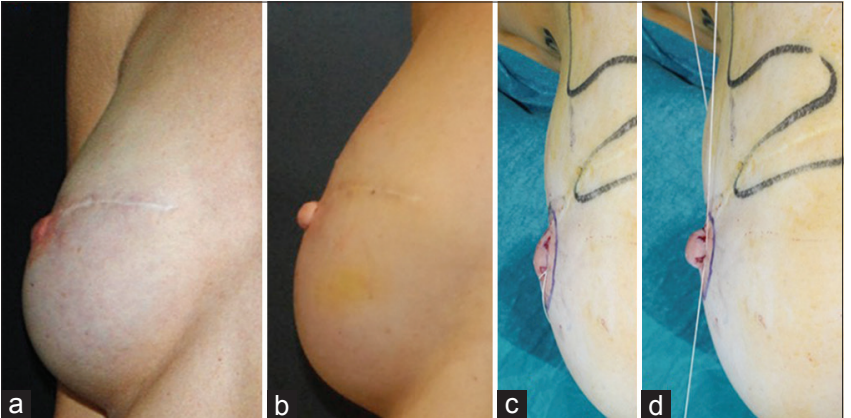

Figure 2: A 48-year-old patient underwent right mastectomy and implant reconstruction 5 years ago. After 1 year, the nipple is reconstructed using a cervical visor flap. (a) In these pre-operative images, we can see the loss of nipple projection; (b) Post-operative images at 12 months, note good nipple projection and minimal scar; (c) Intraoperative view: a purse-string suture is subsequently inserted and continued through all the incisions;

(d) Intraoperative view: the purse-string suture is tied under moderate tension

another donor region or advanced skill. This procedure is a speedy and reliable method for restoring the loss of nipple projection.

\section{Financial support and sponsorship}

\section{Nil.}

\section{Conflicts of interest}

There are no conflicts of interest.

\section{Fabrizio De Biasio, Nicola Zingaretti, Sebastiano Mura, Alessandra Fin, Michele Riccio', Pier Camillo Parodi}

Department of Plastic and Reconstructive Surgery, University of Udine, Udine, ${ }^{1}$ Department of Reconstructive Plastic Surgery-Hand Surgery, Breast Unit, AOU "Ospedali Riuniti," Ancona, Italy

Address for correspondence: Dr. Nicola Zingaretti, Department of Plastic and Reconstructive Surgery, University of Udine, Italy. E-mail: zingarettin@gmail.com

\section{REFERENCES}

1. Caterson SA, Singh M, Talbot SG, Eriksson E. Reconstruction of areolar projection using a purse-string suture technique. Plast Reconstr Surg Glob Open 2015;3:e453.

2. Germanò D, De Biasio F, Piedimonte A, Parodi PC. Nipple reconstruction using the fleur-de-lis flap technique. Aesthetic Plast Surg 2006;30:399-402.

3. Mohamed SA, Parodi PC. A modified technique for nipple-areola complex reconstruction. Indian J Plast Surg 2011;44:76-80.

4. Few JW, Marcus JR, Casas LA, Aitken ME, Redding J. Long-term predictable nipple projection following reconstruction. Plast Reconstr Surg 1999;104:1321-4.
This is an open access article distributed under the terms of the Creative Commons Attribution-NonCommercial-ShareAlike 3.0 License, which allows others to remix, tweak, and build upon the work non-commercially, as long as the author is credited and the new creations are licensed under the identical terms.

\begin{tabular}{|l|l|}
\hline \multicolumn{2}{|c|}{ Access this article online } \\
\hline Quick Response Code: & Website: \\
\hline
\end{tabular}

How to cite this article: De Biasio F, Zingaretti N, Mura S, Fin A, Riccio M, Parodi PC. A new method of salvaging nipple projection after secondary nipple reconstruction using locoregional flap. Indian J Plast Surg 2017;50:107-8.

(c) 2017 Indian Journal of Plastic Surgery | Published by Wolters Kluwer - Medknow 